\title{
Enhanced product quality control through separation of crystallization phenomena in a four-stage MSMPR cascade
}

\section{Supporting Information}

Marie-Christine Lührmann, Jan Timmermann, Gerhard Schembecker and Kerstin Wohlgemuth*

TU Dortmund University, Laboratory of Plant and Process Design, Emil-Figge-Straße 70, 44227 Dortmund, Germany

*Corresponding author: E-mail address: kerstin.wohlgemuth@tu-dortmund.de; Tel.: +49 (0)231755 3020; Fax: +49 (0)231755 2341 


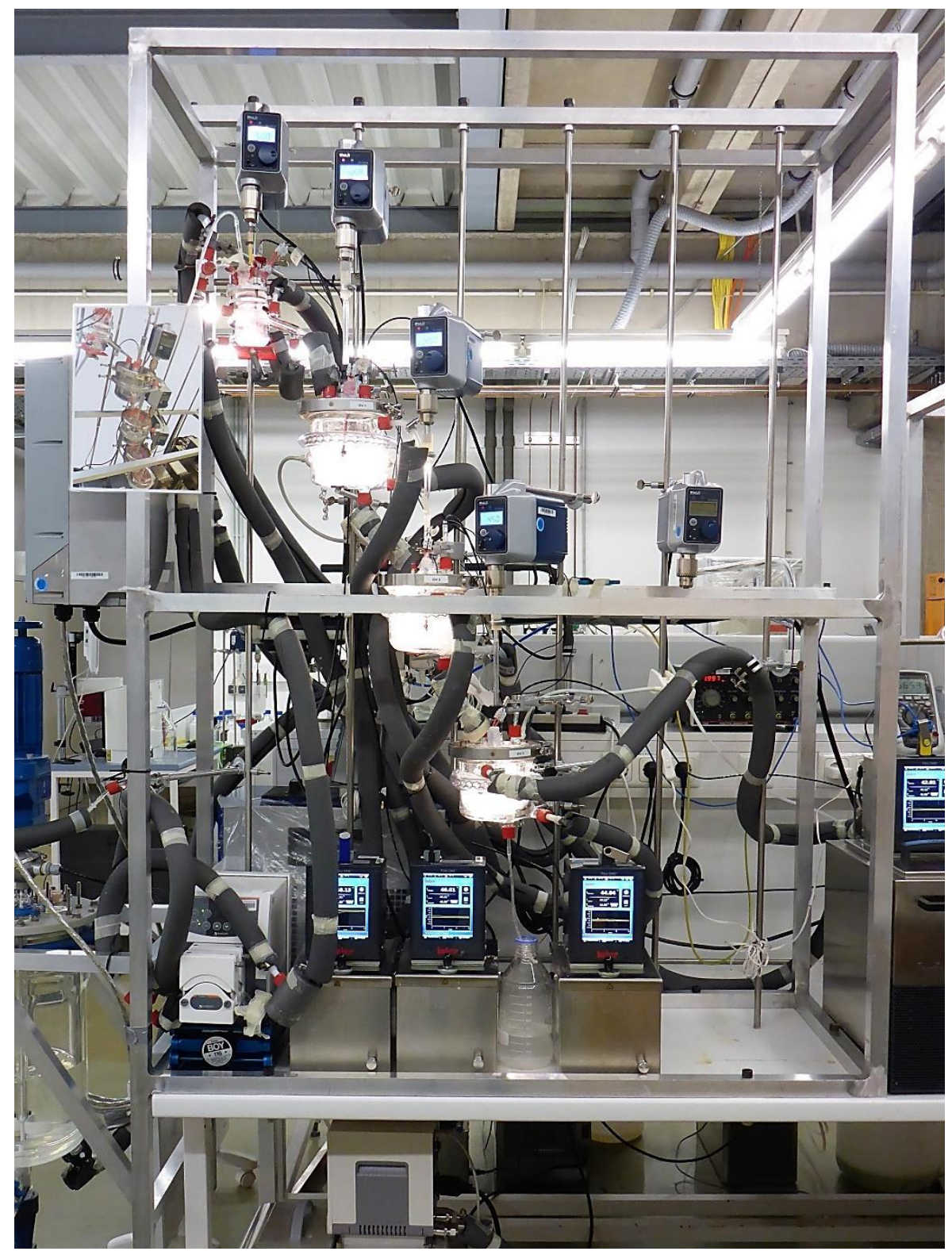

Figure S1: Photograph of the four-stage cascade of MSMPR crystallizers
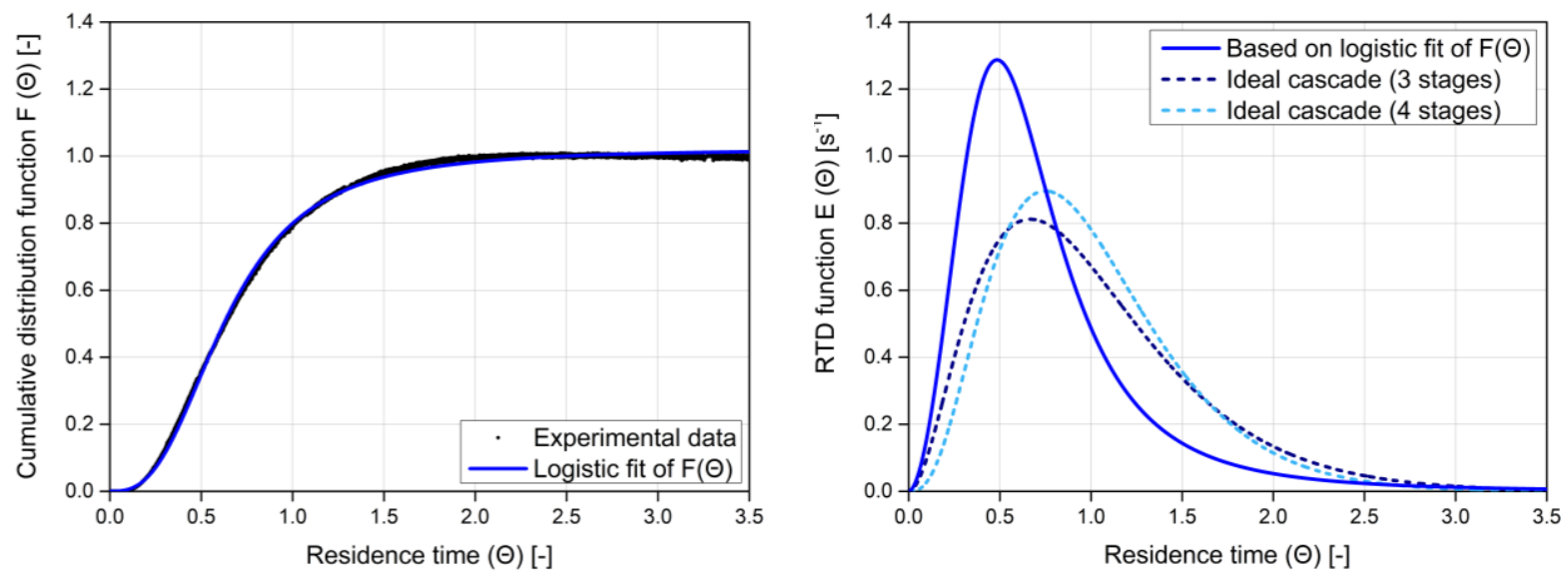

Figure S2: Cumulative distribution function $F$ (left) and RTD function $E$ (right) for the four-stage MSMPR cascade $\left(\dot{V} \approx 10 \mathrm{~mL} \mathrm{~min}^{-1}, \mathrm{n}_{\mathrm{NV}}=500 \mathrm{rpm}, \mathrm{n}_{\mathrm{GV}}=450 \mathrm{rpm}\right)$ 